\title{
We Are All Teachers: Modeling Democratic Engagement in Faculty Development
}

\author{
Morgan Studer \\ Indiana University-Purdue University Indianapolis \\ Melissa Benton \\ John Boner Neighborhood Centers
}

\author{
Christian Rogers \\ Indiana University-Purdue University Indianapolis \\ Michelle Quirke \\ Indiana University-Purdue University Indianapolis
}

As service-learning and community engagement (SLCE) have become increasingly legitimized in higher education as scholarly pedagogical practice, resources to support faculty in learning about and undertaking this engaged work have grown. As Zlotkowski (2015) points out in his framing essay for the SLCE Future Directions Project (FDP), the movement now has "program and course models, disciplinary presentations and publications, research findings, definitions of scholarship, and principles of good practice," all of which continue to be developed and refined (p. 83).

Centers for community engagement, service, service-learning, community-based learning, and teaching and learning more generally provide support and resources for SLCE at many institutions, specifically in the form of faculty development. Helping increase faculty members' ability to understand and implement best practices around community-engaged learning and scholarship is the central focus of much of this faculty development.

As we look toward the future of SLCE, we want to build upon the bold calls of others to increase democratic engagement - engagement enacted with democratic principles and with the understanding that knowledge comes from multiple sources and stakeholders, not simply from the experts of the "academy" - among faculty and community partners, particularly through how we structure faculty development programming. Since strong SLCE involves all stakeholders in doing and being with one another in the work, we call for faculty development opportunities to model practices of co-education, co-learning, and co-designing in and with the community.

Discussions of democratic engagement are not new within the SLCE movement overall or to the SLCE-FDP. Hicks, Seymour, and Puppo (2015) learned in their experience of restructuring traditional approaches to partnership that "democratic relationships among all stakeholders are critical to successful SLCE - being more authentic and more impactful than the all too common relationship between faculty member and community partner in which the faculty member's expertise serves the community member's needs. . .." (p. 106). A common metaphor in SLCE is of bringing people "to the table," which evokes images of hospitality, non-exclusion, and being at the same level when talking and sharing. Tables allow for people to sit together (in circles or in squares), to look into one another's eyes when talking, and to sit at the same "level" as one another. They are also places where we break bread together and can offer one another varying "tastes" of different cultures and traditions. We imagine the democratic relationships Hicks and colleagues describe look much like this image, in which everyone at the table has a voice and can offer her own taste/tradition/culture to the group. As trust and authentic relationships develop, so does the opportunity for deeper engagement.

Beyond such relationship-building, place is also important. Siemers and colleagues posit in their 2015 thought piece "Engaging Place as Partner":

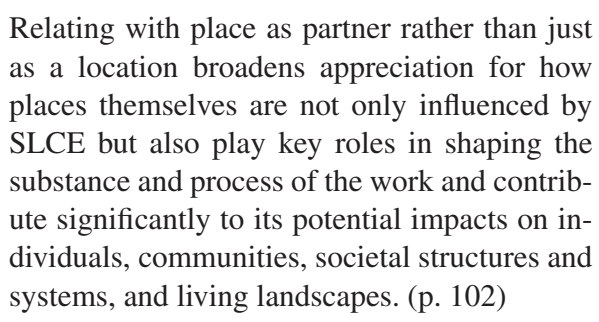

Where we situate our tables matters. Places have stories, traditions, rituals. Engaging democratically with one another where our work is to be taking place matters. This moves faculty and community partners beyond a "placement" mindset - beyond "normalized" engagement, which is "still too often practiced as charity, spectatorship, activity and place, or outreach" - and into deeper understanding of how the community can and should influence the nature and focus of SLCE (Keith, 2016, p. 15). 
Awareness of place as part of the SLCE story helps to avoid the "community as lab" approach.

Faculty development programming is one way we prepare faculty for the often unfamiliar roles and relationships associated with engaging in and with communities. At Indiana University-Purdue University Indianapolis (IUPUI), as with many other institutions supporting community-engaged scholars and practitioners and their community partners and students, our approach to faculty development most often takes the form of campus-based workshops and one-on-one consultations with faculty. Workshops and meetings focused on community partnership development, community project planning, and service-learning course design are all valuable educational tools to help faculty become effective and empowered engaged scholars.

To build upon this traditional form of faculty development and also have community voices at the table, we are developing a model for bringing faculty into the local community to hear directly from and interact with representatives of community organizations. We refer to this as "Community Conversations." As faculty enter the community and come to the table to engage in dialogue with community members, a more democratic approach to faculty development is created. Moderated discussions and opportunities for organic dialogue in the community between IUPUI staff, faculty, and community organization leaders topple the usual dynamics of faculty coming to the community as the "experts."

This attempt to design a more democratic, less faculty-centered space for dialogue helps support co-creation of partnerships and projects among all stakeholders through a community-engaged, place-based approach to faculty development. A key aspect of Community Conversations is for faculty to enter into the community as co-educators and co-learners with community members and other faculty members. Different than one-on-one partnership development approaches (one faculty member meeting with one community member) or university-centric approaches (faculty learn about community from within the walls of the university) or on-campus community partner panel discussions (community members populating panels at the university), this approach emphasizes the importance of place - in particular, the identity of that place in terms of history, culture, politics, rituals - and of entering humbly as learners into relationships with communities.

This more democratic, conversational process creates space for multiple connections among faculty and community partners, which allows for dialogue, learning, and the influx of new and synergistic ideas that may not occur in a one-onone meeting between one faculty member (or one department) and one community member (or community organization). One-on-one conversations are constrained to the knowledge and ideas held between the two parties, making the co-creation of new possibilities less likely than in a setting with multiple interacting sets of ideas. Dialogue allows everyone to learn from one another. Bringing faculty into the community also allows them to get to know the community through experiencing the neighborhood, its residents, and its community organizations rather than through hearing about pieces partially represented at campus events.

Development of the Community Conversations at IUPUI began with a specific opportunity on the Near Eastside of Indianapolis. In February 2016, the John Boner Neighborhood Centers (JBNC) and IUPUI brought together 16 faculty members to learn more about the Near Eastside's designation as the IndyEast Promise Zone (a federal designation established by President Obama in areas of high poverty under which the federal government "partners with local leaders to increase economic activity, improve educational opportunities, leverage private investment, reduce violent crime, enhance public health and address other priorities identified by the community"; https://www.hudexchange. info/programs/promise-zones/promise-zonesoverview/). The presentation at JBNC included information regarding neighborhood initiatives and highlighted existing partnerships with IUPUI. Faculty came to the table to listen, learn, and engage in dialogue about the neighborhood, and some faculty were able to share the successes and challenges of current partnerships with JBNC.

From a community organization perspective, community development work is primarily about building relationships and creating reciprocal opportunities for constituents (such as campus and community) to engage in and benefit from together. As co-author Melissa (community development officer at the JBNC) sees it, Community Conversations are more likely to lead to work that is sustainable in nature because partnerships that develop democratically and more authentically are less likely to be "one off" scenarios that end when one vested group or person leaves the relationship, whether from the campus or the community. The opportunity for dialogue among multiple constituents also allows community organizations to hear a range of ideas from faculty who are given an opportunity to share who they are and the type of projects they currently have (or want) their students doing. The dialogue that occurs may also generate support (or possibilities for support) for the community orga- 
nization's innovative project ideas, including those for which the organization is struggling to find a traditional funding source (often due to its innovative nature).

Two significant partnerships have developed as a direct result of the JBNC Community Conversation, including a new summer outreach program through the IUPUI School of Dentistry and the creation of several videos that will benefit the Centers. These projects allow faculty and students to engage directly with the neighborhood center's participants and neighbors, from children to seniors, and in turn allow program participants and neighbors to see the investment of resources by IUPUI. From Melissa's perspective, to know that students and faculty are invested in and committed to JBNC's mission of making the Near Eastside a more vibrant and thriving place gives residents an increased sense of pride in the neighborhood and the work of the Centers.

Co-author Christian (assistant professor of Computer Graphics Technology at IUPUI) participated in the Near Eastside Community Conversation held at JBNC last year to learn about new possible partnership opportunities for his video production course; he specifically appreciated the meeting taking place in the community because he knew he would get to see and hear ideas from a first-person perspective. Christian's motivation for communityengaged teaching is helping his students develop as engaged citizens who are part of a larger community. Noting that his students take more pride in their work and create better quality products when engaging with actual organizations than when developing fictional content, Christian is committed to creating documentary videos that will fulfill an important objective related to sharing the history of JBNC and its role in the Near Eastside of Indianapolis.

Christian also found value in connecting with other faculty in that community setting. He met a School of Dentistry faculty member and learned of the current partnership between the JBNC and the Indiana University School of Dentistry Student Outreach Clinic. He is now working with this faculty member in using a Web-based application called EASEL to support the learning of student volunteers while they are working in the Student Outreach Clinic; the tool provides reminders during dental procedures and immediate reflection questions after the procedures are completed. As an additional measure, the EASEL team (led by Christian) is also evaluating patient satisfaction to ensure that community members supported by the JBNC receive high quality dental care.

Co-author Michelle (adjunct professor at IUPUI and former clinical assistant professor at the
Indiana University School of Dentistry) turns to community-engaged teaching as a way to connect her students with efforts to reduce health disparities within the community. The JBNC Community Conversation opened her eyes to the work being done on this issue within the community. More importantly, it taught her what makes a community a neighborhood: the feeling of friendship, pride, and ownership that radiated from those who had grown up in the neighborhood as well as the new residents. She was excited to see how the faculty in the meeting were energized to share ideas, search for common interests, and brainstorm ways to work with the JBNC. Discussion at the gathering led to the creation of a dental oral hygiene program that served 90 young people at the JBNC's youth summer camp. From this experience, Michelle built a relationship with the camp director that will generate ongoing engagement opportunities in the neighborhood. The ability to sustain a relationship with a specific person at the JBNC has given her the opportunity to be involved with the summer camp's planning from its early stages and, therefore, better integrate the oral hygiene program into the camp's activities.

Even as Community Conversations have proven to have positive outcomes for both community and campus, we recognize limitations in the current format. The "conversation" can easily slip into a technocratic framework with the community partners serving as the experts (in panel form) or the IUPUI moderator serving as the expert (guiding the discussing through specific questions) with little to no input from the other constituents in the room. Another limitation is simply due to the fact that the "conversation" is bound by time and space and has to date been structured with an agenda formed around predetermined intended outcomes.

We believe relationships are likely most authentic when able to form in an organic way. When we examine deep, long-lasting, organic partnerships, we take away some ideas to inform further development of these Community Conversations in ways that create more thoroughly and deeply some of the conditions that facilitate deeper partnering. For example, this approach can literally take place around tables, with community partners (no longer acting as panelists) sitting in and among campus constituents. The sessions themselves can be formed around issue areas (e.g., sustainability, food security, literacy) rather than neighborhoods, thus bringing together community members and faculty already invested in those specific issues. We continue to be mindful of what conditions best support democratic engagement and will integrate these as we can in future Community Conversations. 
There continue to be bold calls for increasing democratic practices within SLCE, including through this venue of the SLCE-FDP. As we ask faculty to engage in democratic ways with community members and with their students, it is important that we design faculty development programming that models these principles. Faculty development around SLCE should not happen solely within the confines of an academic institution. Offering ways for faculty to connect out in the community, to meet with community organizations in community settings, and to engage in dialogue about community issues helps individuals from campus and community come together on equal footing and build upon one another's strengths, thus laying the groundwork for significant and sustainable democratic partnerships.

\section{References}

Hicks, T., Seymour, L., \& Puppo, A. (2015). Democratic relationships in service-learning: Moving beyond traditional faculty, student, and community partner roles. Michigan Journal of Community Service Learning, 22(1), 105-109.

Keith, N. (2016). Cultivating practitioners of democratic civic engagement. Michigan Journal of Community Service Learning, 23(1), 15-36.

Promise Zones Overview. (n.d.). Retrieved from https:// www.hudexchange.info/programs/promise-zones/ promise-zones-overview/

Siemers, C. K., Harrison, B., Clayton, P. H., \& Stanley, T. A. (2015). Engaging place as partner. Michigan Journal of Community Service Learning, 22(1), 101-105.

Zlotkowski, E. (2015). Twenty years and counting: A framing essay. Michigan Journal of Community Service Learning, 22(1), 82-86.

\section{Authors}

MORGAN STUDER (mohughes@iupui.edu) is the director of Faculty and Community Resources with the Center for Service and Learning at Indiana University-Purdue University Indianapolis (IUPUI). In that capacity she consults with faculty on service-learning course design, develops and leads faculty development workshops and programs, and manages the Service Learning Assistant scholarship program. With a background in Philanthropic Studies and nonprofit management, Morgan's current interests are in community-campus partnership development and leveraging Community WorkStudy as civic engagement.

MELISSA BENTON (mbenton@jbncenters. org) is the community development officer for the John Boner Neighborhood Centers (JBNC). In this role she coordinates the numerous community development initiatives of the JBNC as well as capital building projects and grant activities. Melissa also coordinates and manages special projects for JBNC, including the IndyEast Promise Zone. Melissa and the community development team work to ensure that all JBNC programs and services are aligned with the community's Quality of Life Plan.

CHRISTIAN ROGERS (rogerscb@iupui.edu) is an assistant professor in Computer Graphics Technology in the Purdue School of Engineering \& Technology at Indiana University-Purdue University Indianapolis (IUPUI). He teaches courses ranging from the fundamentals of video production to advanced motion design. His research interests include media theory, experiential learning, and pervasive technology in the area of STEM education.

MICHELLE QUIRKE (mvquirke@iu.edu) is an adjunct professor in University College at Indiana University-Purdue University Indianapolis (IUPUI). She is a registered dental hygienist and a program manager for the Indiana STEM LSAMP project, which is funded through the National Science Foundation. Previously, she was a visiting clinical assistant professor in the Indiana University School of Dentistry and taught introduction to dental hygiene, radiology, and community dental health. 